\title{
PENGARUH FASILITAS KANTOR, KUALITAS PELAYANAN DAN STANDAR OPERASIONAL PROSEDUR TERHADAP TINGKAT KEPUASAN PENGUNJUNG PADA DINAS PERPUSTAKAAN DAN KEARSIPAN DAERAH KABUPATEN BATANGHARI
}

\author{
Ratna, Endang Meiliani
}

STIE Graha Karya Muara Bulian, Jambi, Indonesia

\begin{abstract}
This study uses primary data obtained by distributing question naires to visitors Dinas Perpustakaan dan Kearsipan Daerah Kabupaten Batang Hari. The population of this study amounted to 1,029 people with a total sample of 92 respondents. The analytical tool used is the Likert scale and scale range. From the research shows the condition of Office Facilities in the Regional Dinas Perpustakaan dan Kearsipan Daerah Kabupaten Batang Hari is known as an average index value of $\mathbf{3 . 6 3}$ or categorized as Good, because the Regional Library and Archives Service has training facilities for visitors. From the research shows that Service Quality in the Regional Dinas Perpustakaan dan Kearsipan Daerah Kabupaten Batang Hari is known as the average index value of $\mathbf{3 . 6 2}$ is in the Good category, because the Regional Library and Archives Service Provides polite and attentive service to visitors. From the study shows the Standard Operating Procedure at the Dinas Perpustakaan dan Kearsipan Daerah Kabupaten Batang Hari District, it is known that the average index value of $\mathbf{3 . 6 1}$ is in the Good category, because the Regional Library and Archives Service has procedures that are in accordance with the applicable legal basis. From the research shows that the visitors' satisfaction at the Dinas Perpustakaan dan Kearsipan Daerah Kabupaten Batang Hari is known as the average index value of 3.68 is in the Good category, because the visitors of the Regional Library and Archives Service are satisfied with the real, trusted, responsive, polite and confident services give it
\end{abstract}

Keywords: Marketing Management, Marketing services, Facilities, service quality, Standard Operating Procedures, and Satisfaction.

\section{PENDAHULUAN}

Perusahaan sektor jasa pada saat ini telah mengalami peningkatan yang signifikan dan dramatis dibanding waktu sebelumnya. Seiring dengan meningkatnya kesejahteraan masyarakat maka konsumsi akan barang dan jasa semakin meningkat. Konsumsi jasa, terutama pendidikan, kesehatan , hiburan, komunikasi, keuangan dan traveling adalah sektor jasa yang banyak dikonsumsi dan memiliki pengaruh besar terhadap perkembangan perekonomian. Ada berbagai macam faktor yang bisa mempengaruhi perkembangan bisnis jasa seperti perubahan demografis, perubahan psikologis, sosial, perekonomian, politik dan hukum.

Khusus di dunia Pendidikan dan ilmu pengetahuan fasilitas jasa seperti buku bacaan merupakan penentu dalam membantu dalam meningkatkan kecerdasan kehidupan suatu bangsa. Semakin tinggi tingkat pendidikan dan ilmu pengetahuan suatu bangsa maka sudah pasti bangsa tersebut akan menjadi bangsa yang maju dan terdepan.

Memasuki era globalisasi seperti saat ini masyarakat mulai menginginkan segala sesuatu yang terbaru dan lebih modern sebagai tolak ukur menuju modernisasi. Begitu juga dengan dunia baca tulis. Masyarakat pun mulai menyadari bahwa ilmu pengetahuan sangat penting untuk menunjang masa depan masyarakat itu sendiri. Dan untuk menunjang semua itu dibutuhkan fasilitas yang memadai sebagai penunjang keberhasilan dalam proses belajar.

Dinas Perpustakaan dan Kearsipan Daerah Kabupaten Batang Hari yang terletak di kecamatan Muara Bulian hadir sebagai wadah mencari data dan sumber ilmu yang relevan dan faktual. Kondisi lingkungan kantor yang mudah di jangkau akan memudahkan masyarakat untuk mendapatkan manfaat dari keberadaan 
kantor Dinas Perpustakaan dan Kearsipan Daerah Kabupaten Batang Hari.Akan tetapi keberadaannya juga harus ditunjang dengan fasilitas yang memadai. Fasilitas merupakan segala sesuatu yang sengaja disediakan oleh penyedia jasa untuk dipakai serta dinikmati oleh konsumen yang bertujuan memberikan tingkat kepuasan yang maksimal. Fasilitas tersebut dapat berupa kelengkapan buku, pendingin ruangan dan fasilitas lain yang menunjang kemudahan dalam mengakses informasi dan ilmu pengetahuan.

Kotler menyebutkan bahwa pelayanan (Service) dapat didefinisikan sebagai suatu tindakan atau kinerja yang diberikan oleh seseorang kepada orang lain. Oleh karena itu pelayanan harus maksimal agar apa yang di inginkan dapat terpenuhi dengan maksimal dengan begitu pengunjung akan merasa puas. Pelayanan dapat berupa senyum sapa dari petugas kepada pengunjung, juga dapat berupa pemberian petunjuk mengenai tata tertib yang ada di dalamnya.

Untuk meningkatkan dan maksimalisasi pelayanan maka di buatlah Standar Operasional Prosedur adalah pedoman atau acuan untuk melaksanakan tugas pekerjaan sesuai dengan fungsi dan alat penilaian kinerja instasi pemerintah berdasarkan indikator indikator teknis, administrasif dan prosedural sesuai dengan tata kerja, prosedur kerja dan sistem kerja pada unit kerja yang bersangkutan. Tujuan Standar Operasional Prosedur adalah menciptakan komitmen mengenai apa yang dikerjakan oleh satuan unit kerja instansi pemerintahan untuk mewujudkan good governance.

\section{METODE PENELITIAN}

\section{Jenis Penelitian}

Jenis metode penelitian yang digunakan dalam melakukan penelitian ini adalah metode deskriptif dan verifikatif. Metode deskriptif adalah metode penelitian yang bertujuan untuk menggambarkan, menjelaskan keadaan yang ada pada Dinas Perpustakaan dan
Kearsipan Daerah Kabupaten Batanghari berdasarkan fakta, sifat-sifat populasi dan data-data yang telah dikumpulkan kemudian disusun secara sistematis dan selanjutnya dianalisis untuk diambil kesimpulan. Sedangkan metode verifikatif adalah metode yang digunakan untuk mengetahui kebenaran hipotesis dengan menggunakan perhitungan statistik (Sugiyono, 2010).

\section{Jenis dan Sumber Data Jenis Data}

Data Kualitatif, adalah data yang bukan dalam bentuk angka atau tidak dapat dihitung dalam bentuk bilangan rill, dan diperoleh dari wawancara dari pihak perusahaan, karyawan dan konsumen serta sebagai informasi yang diperoleh yang berkaitan dengan masalah yang tengah diteliti.

Data kuantitatif, adalah data yang diperoleh dalam bentuk angka-angka yang dapat dihitung, yang diperoleh dari kuesioner yang bagikan dan berhubungan dengan masalah yang diteliti.

\section{Sumber Data}

a. Data Primer : Menurut Andi Supangat (2010:2) mendefinisikan bahwa: "Data Primer yaitu data yang diperoleh secara langsung dari objek yang diteliti, baik dari objek individual (responden) maupun dari suatu instansi yang dengan sengaja melakukan pengumpulan data dari instansi-instansi atau badan lainnya untuk keperluan penelitian dari pengguna".

b. Data Sekunder : Menurut Jogiyanto (2010:137) mendefinisikan bahwa:"Sumber data sekunder merupakan sumber yang tidak langsung memberikan data kepada pengumpul data, misalnya lewat orang lain atau lewat dokumen".

\section{Metode Pengumpulan Data}

Metode pengumpulan data yang digunakan dalam penelitian ini adalah sebagai berikut: 1) Penelitian Perpustakaan; 2) Penelitian Kelapangan (Wawancara, 
Pengamatan, Kuisioner)

\section{Populasi dan Sampel}

a. Populasi : Populasi adalah sekelompok objek yang akan diteliti (Arikunto, 2012)

b. Sampel : Menurut Sugiyono (2012:120) menjelaskan bahwa bila populasi besar dan penelitian tidak mungkin mempelajari semua yang ada pada populasi, misalnya karena keterbatasan dana, tenaga dan waktu, maka peneliti dapat menggunakan sampel yang diambil dalam populasi itu. Apa yang dipelajari dari sampel itu kesimpulannya akan diberlakukan untuk populasi, untuk itu sampel dan populasi harus benarbenar mewakili.

\section{Metode Analisis}

Dalam pembahasan dan penganalisaan masalah akan digunakan metode deskriptif kuantitatif. Metode deskriptif kuantitatif merupakan suatu teknik yang menggambarkan, menginterprestasikan arti data-data yang telah terkumpul dengan memberikan perhatian dan merekam sebanyak mungkin aspek situasi yang diteliti pada saat itu, sehingga memperoleh gambaran secara umum dan menyeluruh tentang keadaan sebenarnya.

\section{Alat Analisa}

\section{a. Skala Likert}

Indikator-indikator di ukur dengan penilaian likert yang memiliki lima tingkat jawaban yang masing-masing mempunyai nilai $1-5$ dengan rincian sebagai berikut :

1) Sangat Tidak Setuju (STS) : 1

2) Tidak Setuju (TS) : :2

3) Cukup Setuju (CS) : 3

4) Setuju (S) : 4

5) Sangat Setuju (SS) : 5

Tabel 1. Indeks penilaian Jawaban Responden

\begin{tabular}{cc}
\hline Bobot/ Nilai & Penilaian \\
\hline $1,00 \leq \mathrm{x} \leq 1,80$ & Sangat Tidak Baik \\
$1,81 \leq \mathrm{x} \leq 2,60$ & Tidak Baik \\
$2,61 \leq \mathrm{x} \leq 3,40$ & Cukup Baik \\
$3,41 \leq \mathrm{x} \leq 4,20$ & Baik \\
$4,21 \leq \mathrm{x} \leq 5,00$ & Sangat Baik. \\
\hline
\end{tabular}

\section{b. Uji Validitas}

Menurut Arikunto fungsi validitas adalah untuk mengatahui tingkat kevalidan dari instrument (Kuisioner) yang digunakan dalam pengumpulan data.

\section{c. Uji Realibilitas}

Uji realibilitas menunjukkan pada adanya konsistensi dan stabilitas nilai hasil pada pengukuran tertentu disetiap kali pengukuran dilakukan pada hal yang sama (Jonathan Sawarno,2012).

\section{d. Analisa Regresi Berganda}

Untuk mengetahui hubungan dan pengaruh antara Fasilitas Kantor,Kualitas Pelayanan dan Standar Operasional Prosedur Terhadap Kepuasan Pengunjung, maka digunakan teknik analisis regresi linier berganda, untuk mengetahui besarnya pengaruh secara kuantitatif dari suatu perubahan (variabel $\mathrm{X}$ ) terhadap kejadian lainnya (variabel $Y$ ). analisis regresi menggunakan rumus persamaan regresi berganda seperti yang di kutip dalam Sugiyono (2012: 277), yaitu :

$$
Y=a+b_{1} X_{1}+b_{2} X_{2}+b_{3} X_{3}+e
$$

\section{e. Uji t ( Uji Parsial)}

Uji $t$ ini digunakan untuk menguji koefisien regresi secara individual yaitu pengaruh antara variabel independenan (Fasilitas Kantor, Kualitas Pelayanan dan Standar Operasional Prosedur) dengan variabel dependen (Kepuasan Pengunjung).

\section{f. Koefisien Determinasi $\left(R^{2}\right)$}

Menurut Santoso (2011: 278) koefisien determinasi $\mathrm{R}$ square $\left(\mathrm{R}^{2}\right)$ di gunakan untuk menjelaskan besaran (secara persentase) pengaruh bebas terhadap variabel terikat. Nilai $\mathrm{R}^{2}$ berkisar nol hingga satu $\left(0<\mathrm{R}^{2}<1\right)$, semakin mendekati nol maka semakin kecil kontribusi pengaruhnya, dan semakin mendekati satu semakin besar pengaruh variabel bebas terhadap variabel terikat.

$$
\mathrm{KD}=\mathbf{r}^{2} \times 100 \%
$$


HASIL DAN PEMBAHASAN

Fasilitas Kantor pada Dinas Perpustakaan dan Kearsipan Daerah Kabupaten Batang Hari

Fasilitas kantor adalah sarana pendukung dalam aktivitas perusahaan berbentuk fisik, dan digunakan dalam kegiatan normal perusahaan, memiliki jangka waktu kegunaan yang relatif permanen, dan memberikan manfaat untuk masa yang akan datang.

Bagi perusahaan kegiatan maintenance sudah menjadi dwi fungsi, yaitu pelaksanaan dan kesadaran untuk melakukan pemeliharaan terhadap fasilitasfasilitas produksi.Dari beberapa indikator pernyataan di atas didapatlah bahwa jawaban responden yang memiliki nilai tertinggi adalah "Dinas Perpustakaan dan Kearsipan Daerah memiliki sarana latihan bagi pengunjung", dengan jumlah 338 poin dan indeks 3,67 dari 92 responden, yang berarti pada pernyataan tersebut tanggapan responden mayoritas menyatakan Baik.

Sedangkan jawaban responden yang memiliki nilai terendah adalah "Dinas Perpustakaan dan Kearsipan Daerah memiliki fasilitas berupa komputer yang mudah di akses", dengan jumlah 328 poin dan indeks 3,57 dari 92 responden, yang berarti pada pernyataan tersebut tanggapan responden mayoritas menyatakan Baik.

Hasil jawaban responden terhadap variabel Fasilitas Kantor dengan nilai ratarata indeks 3,63 adalah Baik, karena Dinas Perpustakaan dan Kearsipan Daerah memiliki sarana latihan bagi pengunjung yang datang.

\section{Kualitas Pelayanan pada Dinas Perpustakaan dan Kearsipan Daerah Kabupaten Batang Hari}

Kualitas pelayanan merupakan totalitas dari bentuk karakteristik barang dan jasa yang menunjukkan kemampuannya untuk memuaskan kebutuhan pelanggan, baik yang nampak jelas maupun yang tersembunyi. Bagi perusahaan yang bergerak di sektor jasa, pemberian pelayanan yang berkualitas pada pelanggan merupakan hal mutlak yang harus dilakukan apabila perusahaan ingin mencapai keberhasilan..Dari beberapa indikator pernyataan di atas didapatlah bahwa jawaban responden yang memiliki nilai tertinggi adalah "Dinas Perpustakaan dan Kearsipan Daerah Memberi pelayanan dengan santun dan penuh perhatian kepada pengunjung", dengan jumlah 338 poin dan indeks 3,67 dari 92 responden, yang berarti pada pernyataan tersebut tanggapan responden mayoritas menyatakan Baik.

Sedangkan jawaban responden yang memiliki nilai terendah adalah "Dinas Perpustakaan dan Kearsipan Daerah dapat memberi keyakinan kepada pengunjung", dengan jumlah 327 poin dan indeks 3,55 dari 92 responden, yang berarti pada pernyataan tersebut tanggapan responden mayoritas menyatakan Baik. Hasil jawaban responden terhadap variabel Kualitas Pelayanan memiliki nilai rata-rata indeks 3,62 termasuk kategori Baik, karena Dinas Perpustakaan dan Kearsipan Daerah Memberi pelayanan dengan santun dan penuh perhatian kepada pengunjung.

\section{Standar Operasinal Prosedur pada Dinas Perpustakaan dan Kearsipan Daerah Kabupaten Batang Hari}

Standar Operasional Prosedur (SOP) meliputi seluruh proses penyelenggaraan administrasi pemerintahan termasuk pemberian pelayanan baik pelayanan internal maupun eksternal yang diksanakan oleh unit kerja di lingkungan kerja. Dari beberapa indikator pernyataan di atas didapatlah bahwa jawaban responden yang memiliki nilai tertinggi adalah "Dinas Perpustakaan dan Kearsipan Daerah memiliki Prosedur yang sesuai dengan landasan hukum yang berlaku", dengan jumlah 337 poin dan indeks 3,66 dari 92 responden, yang berarti pada pernyataan tersebut tanggapan responden mayoritas menyatakan Baik.

Sedangkan jawaban responden yang memiliki nilai terendah adalah "Dinas Perpustakaan dan Kearsipan Daerah memiliki SOP yang berlaku selaras dengan 
visi dan misi",dan "Dinas Perpustakaan danKearsipan Daerah memiliki SOP yang berorientasikepadakemudahanpengunjung" dengan jumlah yang sama yaitu328 poin dan indeks 3,57 dari 92 responden, yang berarti pada pernyataan tersebut tanggapan responden mayoritas menyatakan Baik. Hasil jawaban responden mengenai Standar Operasional Prosedurmemiliki nilai ratarata indeks 3,61 termasuk kategoriBaik, karena Dinas Perpustakaan dan Kearsipan Daerah memiliki Prosedur yang sesuai dengan landasan hukum yang berlaku.

\section{Kepuasan Pengunjung pada Dinas Perpustakaan dan Kearsipan Daerah Kabupaten Batang Hari}

Kepuasan pelanggan adalah perbandingan antara persepsi konsumen terhadap produk atau jasa dalam kaitannya dengan harapan mereka masingmasing. Di sisi positif, konsumen yang merasa puas akan menjadi loyal dan akan melakukan pembelian kembali atau orangorang yang mendapatkan pengalaman melebihi ekspetasinya dan yang paling menguntungkan adalah adanya promosi dari mulut ke mulut. Dari beberapa indikator pernyataan di atas didapatlah bahwa jawaban responden yang memiliki nilai tertinggi adalah "Pengunjung Dinas Perpustakaan dan Kearsipan Daerah puas dengan pelayanan nyata,terpercaya, cepat tanggap, sopan santun dan keyakinan yang di berikan", dengan jumlah 346 poin dan indeks 3,76 dari 92 responden, yang berarti pada pernyataan tersebut tanggapan responden mayoritas menyatakan Baik.

Sedangkan jawaban responden yang memiliki nilai terendah adalah "Pengunjung Dinas Perpustakaan dan Kearsipan Daerah puas dengan adanya standar yang sesuai visi dan misi,dan pelayanan yang berorientasi kepada pengunjung", dengan jumlah poin yaitu330 poin dan indeks 3,59 dari 92 responden, yang berarti pada pernyataan tersebut tanggapan responden mayoritas menyatakan Baik. Hasil jawaban responden mengenai Kepuasan Pengunjung memiliki nilai rata-rata indeks $\mathbf{3 , 6 8}$ termasuk kategori Baik, karena Pengunjung Dinas Perpustakaan dan Kearsipan Daerah puas dengan pelayanan nyata, terpercaya, cepat tanggap, sopan santun dan keyakinan yang di berikan.

\section{SIMPULAN}

Berdasarkan penelitian dan pembahasan yang telah diuraikan, maka dapat ditarik kesimpulan sebagai berikut: 1 . Dari hasil penelitian atas fasilitas kantor pada Dinas Perpustakaan dan Kearsipan Daerah Kabupaten Batang Hari, dapat dilihat rata-rata indeks sebesar 3,63 atau dikategorikan Baik, karena Dinas Perpustakaan dan Kearsipan Daerah memiliki sarana latihan bagi pengunjung yang dating. 2. Dari hasil penelitian atas kualitas pelayanan pada Dinas Perpustakaan dan Kearsipan Daerah Kabupaten Batang Hari, dapat dilihat ratarata indeks sebesar 3,62 atau dikategorikan Baik, karena karena Dinas Perpustakaan dan Kearsipan Daerah Memberi pelayanan dengan santun dan penuh perhatian kepada pengunjung. 3. Dari hasil penelitian atasStandar Operasional Prosedur (SOP) pada Dinas Perpustakaan dan Kearsipan Daerah Kabupaten Batang Hari dapat dilihat rata-rata indeks sebesar 3,61 atau dikategorikan Baik, karena Dinas Perpustakaan dan Kearsipan Daerah memiliki Prosedur yang sesuai dengan landasan hukum yang berlaku. 4. Dari hasil penelitian atas Kepuasan Pengunjung pada Dinas Perpustakaan dan Kearsipan Daerah Kabupaten Batang Hari, dapat dilihat ratarata indeks sebesar 3,68 atau dikategorikan Baik, karena Pengunjung Dinas Perpustakaan dan Kearsipan Daerah puas dengan pelayanan nyata,terpercaya, cepat tanggap, sopan santun dan keyakinan yang di berikan. 5. Dari hasil Uji t, Untuk Fasilitas Kantor $\left(\mathrm{X}_{1}\right)$ ternyata dengan angka

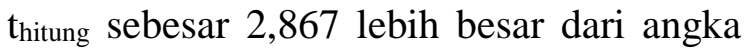
$\mathrm{t}_{\text {tabel } 1,66256}(2,867>1,66256)$, untuk Kualitas Pelayanan $\left(\mathrm{X}_{2}\right)$ ternyata dengan angka thitung sebesar 3,276 lebih besar dari angka $t_{\text {tabel }} 1,66256(3,276>1,66256)$, untuk 
Standar Operasional Prosedur $\left(\mathrm{X}_{3}\right)$ ternyata dengan angka $t_{\text {hitung }}$ sebesar 3,072 lebih besar dari angka $\mathrm{t}_{\text {tabel }} 1,66256$ $(3,072>1,66256)$. Dari hasil perhitungan statistik Uji $F$ pada tabel ANOVA diperoleh nilai $F_{\text {hitung }}$ lebih besar dari $F_{\text {tabel }}$ $(200,406>3,10)$, maka dapat dinyatakan variabel Fasilitas Kantor $\left(\mathrm{X}_{1}\right)$, Kualitas Pelayanan $\left(\mathrm{X}_{2}\right)$ dan Standar Operasional Prosedur berpengaruh secara simultan terhadap variabel dependen Kepuasan Pengunjung(Y).

\section{DAFTAR PUSTAKA}

Abdul Majid, S. 2011. Customer service dalam bisnis jasa transportasi. Jakarta: PT Raja Grafindo Persada.

Abdullah, Faisal. 2011. Dasar-Dasar Manajemen Keuangan. Edisi Pertama. Malang: Universitas Muhammadiyah.

Andi Supangat. 2010. Statistik Dalam Kajian Deskriptif, Inferensi, Dan Non Parametrik. Jakarta: Kencana Prenada Media Group.

Anwar Prabu Mangkunegara. 2015. Manajemen Sumber Daya Manusia. Bandung: PT. Remaja Rosda Karya.

Dharmmesta, Swastha B, Handoko, Hani T. 2012. Manajemen Pemasaran Analisis Perilaku Konsumen. EdisiPertama. Yogyakarta: BPFE.

Hardiyansyah. 2011. Kualitas Pelayanan Publik, Konsep, Dimensi, Indikator Dan Implementasinya. Yogyakarta: Gava Media.

Husein Umar. 2010. Metode Penelitian Untuk Skripsi Dan Tesis. Jakarta: Rajawali

Jonathan Sarwono. 2012. Metode Penelitian Kuantitatif \& Kualitatif. Yogyakarta: Graha Ilmu.

Kotler\& Armstrong. 2011. Prinsip-Prinsip Pemasaran 2.Edisi Kedua Belas. Jakarta: Erlangga.

Manullang, M. dan Esterlina Hutabarat. 2016. Manajemen pemasaran jasa. Yogyakarta: IndomediaPustaka.
Moleong, Lexy J. 2013. Metodologi Penelitian Kuantitatif. Bandung: PT RemajaRosdakarya.

Sugiyono. 2014. Metode Penelitian Kuantitatif, Kualitatif, Dan $R \& D$. Bandung: Alfabeta.

Sulistiyana.Djamhur, Hamid Dan Devi Farah Azizah. 2014. Pengaruh Fasilitas Wisata Dan Harga Terhadap Kepuasan Konsumen (StudiPada Museum Satwa). Jurnal Administrasi Bisnis. Vol. 25 No. 1 Agustus 2015.

https://www.blogspot.co.id/fasilitaskantor.html. Diakses 27Maret 2018. Fasilitaskantor. 